\title{
Macroeconomic signs of an innovative economy by the case of Great Britain
}

\author{
Mikhail Savelyev ${ }^{1 *}$, Mikhail Kozyrev ${ }^{1}$, Andrey Savchenko ${ }^{1}$, Vladimir Koretsky ${ }^{2}$, Rail Galiakhmetov ${ }^{2}$ \\ ${ }^{1}$ Mitra Association, Pushkinskaya Str. 241, 60, 426008 Izhevsk, Russia \\ ${ }^{2}$ FSBEI HE M.T. Kalashnikov IzhSTU, Studencheskaya Str. 7, 426069Izhevsk, Russia
}

\begin{abstract}
By the case of the economic development of Great Britain, the hypothesis was verified that innovations at the macroeconomic level should accelerate economic growth and at the same time reduce development risks, stabilizing this growth, reducing its fluctuations under the influence of market factors. The economic development of Great Britain is investigated in 25 economic cycles for the period from 1830-2020. Economic development was investigated according to the parameters of economic growth and development risk in each of the considered cycles. Four types of economic development policy are theoretically described in terms of the dynamics of changes in growth and risk between the previous and subsequent cycles including progressive, regressive, aggressive and conservative. In relation to the identified periods of progressive development policy in Great Britain, the institutional innovations that led to this type of development were investigated. Among them was the great economic reform of the early Victorian era, the course of social or new liberalism and the popular budget before the First World War, the activities of the first Labor government immediately after this war, economic recovery after World War II in combination with the Marshall plan and nationalization, the era of the Conservatives and the politics of New Labor at the end of the 20th century. The study showed that the implementation of authentic national culture and institutions complementary to the existing authentic culture institutions of institutional innovations leads to a simultaneous decrease in the risk of development and acceleration of economic growth, which can be considered the most favorable policy of macroeconomic management of entrepreneurial activity in order to accelerate the application of technical and commercial innovations.
\end{abstract}

\section{Introduction}

The issue of managing innovative activity in the postindustrial world is acquiring basic, strategic importance for economic development, since innovations have become the main source of wealth, and not merely an additional factor of competitiveness, as it was peculiar for the industrial era. At the same time, economic science does not give an unambiguous answer with what tools, methods, means, institutions it is possible to effect on the subtle matters of the creativity of innovators and the activity of entrepreneurs.

Most researchers identify practices of influence at the microeconomic level: creating conditions for innovative activities of organizations. At the macroeconomic management level, research does not go beyond descriptive classifications. For example, one of the first to analyze the results of economic activity over long historical periods was A. Maddison [1], who widely used the methods of quantitative analysis (quantification) as a tool for historical analysis.

The work of W. Easterly and R. Levin shows the formation of modern empirical patterns of economic growth, such as, for example, the growing gap in the levels of GDP per capita between countries, national policies and their impact on long-term economic growth, etc. [2].

Conclusions on the importance of the influence of various factors, including cultural and institutional, on the country's macroeconomic indicators are presented in the works of other authors [3-5].

The descriptions of microeconomic models of innovation policy are more specific. For example, some the authors [6] identify three basic models of innovative development "Euro-Atlantic", which includes the British, "East Asian" and "alternative" and investigate their main features. The authors note that after the Second World War, European countries radically changed their research priorities, focusing on relatively cheap ways to obtain scientific and technical information. An illustrative example is Great Britain, which abandoned fundamental and costly research in the field of nuclear physics (with the exception of those directly related to the production of nuclear weapons). Radio astronomy and the study of the biological properties of high-molecular substances were chosen as the priority directions, where it achieved considerable success, laying the foundation for the creation of two

*Corresponding author: savaisai@gmail/.com 
fundamental scientific disciplines - astrophysics and molecular biology.

In all other respects, the British innovation system, centered around a small number of top-class universities, copies the US innovation system, where universities are the basis of the national innovation system (hereinafter NIS).

The newest model for the formation of the NIS, which was developed on the basis of the Euro-Atlantic model, is the triple helix model. In its finished form, it does not yet exist in any country. It received the greatest development in the USA, and its individual elements - in some developed countries of Western Europe, Brazil and Japan. The basis of this concept lies in the fact that in the chain "universities - business - government", it is universities that play an increasingly important role in a knowledge-oriented economy [7-10]. The triple helix idea is based on the synthesis of a number of sociological theories, the use of analogies from the biological sciences, as well as the similarity of the problem of the relative motion of three bodies, which does not have a general solution, but particular solutions are possible for some specific initial conditions. With regard to innovative development, the triple helix model describes the interaction of three institutions (sciencestate-business) at each stage of creating an innovative product. This is a dynamic model of interorganizational interactions that arises in the course of the evolution of the economy and society.

Moreover, to achieve synergy, network participants need to be in a mode of constant coordination (collaboration mode) [11].

Some researchers divide the stakeholders in the innovation process into groups. For example, H. Liu and S. Wyat distinguish primary (directly involved in innovation) and secondary (influencing the behavior of primary subjects) subjects, as well as institutions that affect the behavior of subjects of both groups [12].

At the same time, according to S. Botot and D. Satinsky [13], the triple helix model is a model of regional economic development, and not a model of national innovation policy in general.

At present, a complicated type of the triple helix model is being developed abroad - the four-link helix model described in 2009 by Y. Karayannis [14]. This model concerns interactive networking at the level of the entire national community, and not just between the three leading institutional sectors. Since other institutions, represented by various social strata, began to impact the innovation process, this circumstance found its theoretical embodiment in the addition of a fourth element to the triple helix, embracing representatives of civil society. It is believed that the fourth spiral characterizes the modern postindustrial economy better than the triple one, since in the 21 st century. Civil society is acquiring a critical role in the creation and dissemination of new goods and values.

The principle of the four-link helix increases the likelihood of successful implementation by regional politicians of a locally-oriented entrepreneurial process, which stimulates intensive experimentation and invention and, at the same time, stimulates innovation [15].

Citizens not only participate in the actual development process, but can also propose new types of innovations; as a result, connections are established between users and other "actors" in industry, science or government [16].

This enables conclusion that for a number of countries the possibility of resorting to the Euro-Atlantic model of innovative development, despite all their advantages, is essentially closed to be made. Efforts to create fundamental science or a full high-tech cycle would not only require them to bear unbearable financial, time and organizational costs, but, most likely, would run into insurmountable obstacles in the form of peculiarities of national culture and psychology.

An alternative model, developed in accordance with the specifics of national culture, national psychology and traditions, enables these countries to join innovative development, turning national features into competitive advantages. Of the newly industrialized countries at the moment, only China, in addition to the simultaneous application of import substitution and export orientation strategies, is trying to implement a strategy of technological leadership.

This research is within the framework of this alternative model, which assumes that there are mechanisms for the interaction of culture with the institutional support of economic activity, and if these elements of macroeconomic management correspond to each other, they provide an opportunity for innovative development. At the same time, the set of successful institutional instruments is specific to each culture. We have presented the results of these studies in a number of works: both in the development of theoretical models and in the phenomenological description of various historical and cultural communities, civilizations and cultures [17].

This view of the search for the competitive advantages of economic development allows us to significantly expand the historical horizon of research on innovation management even beyond the industrial era. To the extent that the existing quantitative economic development database allows us to do so.

Research hypothesis. A decline in economic growth is traditionally associated with a decline in entrepreneurial activity and innovation. The increase in risk with the acceleration of economic growth speaks primarily of the opportunistic rather than innovative reason for the increase in entrepreneurial activity. This growth is usually unstable. Based on this, it is assumed that innovations at the macroeconomic level should accelerate economic growth and at the same time reduce development risks, stabilizing this growth, reducing its fluctuations under the influence of market factors. It is assumed that progressive economic development occurs due to institutional transformations that are authentic to 
culture and complementary to existing institutions of authentic culture.

To verify this hypothesis, an object is required that, over the longest possible period of time, has sufficiently reliable information about economic development in the absence of hostilities, large-scale social conflicts and revolutionary changes in the socio-economic system and political and legal structure on its territory. The United Kingdom best meets these criteria. In addition, this country has been a world economic leader for a long period of time. And after losing its leadership, the UK remains one of the largest national economies in the world. This position of the country also increases the likelihood of verifying the hypothesis, since it excludes distortions of economic indicators due to external influences or random phenomena.

\section{Materials and Methods}

The object of our research is the UK economy from 1830 to 2020. The periods are divided into 25 economic cycles. The economic cycle is defined as the period from the first year of growth or acceleration of economic growth to the last year of decline or slowdown in growth.

The subject is the search for changes in essential parameters of economic development between the previous and subsequent cycles, characterized by a simultaneous decrease in the risk of development and the acceleration of economic growth, as well as a phenomenological description of the institutional innovations that led to these changes.

The traditional use of only indicators of economic growth in macroeconomic studies is not informative enough. In this regard, by analogy with the technical analysis of the profitability of securities, the standard deviation of the average annual growth rates of real GDP was used as an indicator of stability.

The research method is a comparative statistical analysis of growth and risk indicators: the average annual growth rate of real GDP and the standard deviation of the same indicator, as a characteristic of its stability, are determined for each economic cycle.

If the subsequent period compared to the previous one had a lower risk indicator and a higher growth rate, then such changes in economic development can be considered progressive, the reverse change - regressive. If risks and growth are falling, then such development can be considered conservative, and if they grow, aggressive.

Initial data for analysis are data from Angus Maddison Historical Statistics database [18] up to 2008, and from 2009 up to 2020 from The Conference Board, Total Economy Database [19].

The periods for analysis are identified taking into account economic cycles. A total of 25 periods have been identified: 1830-1837, 1838-1842, 1843-1850. 1851-1855, 1856-1867, 1868-1879, 1880-1885, 18861892, 1893-1903, 1904-1908, 1909-1914, 1915- 1921, 1922-1926, 1927-1939, 1940-1947, 1948-1952, 1953-
1958, 1959-1962, 1963-1969, 1970-1975, 1976-1981, 1982-1991, 1992-2001, 2002-2009, 2010-2020 and are grouped by known historical eras.

This research method is described in detail in [20] and applied to study the development of Russia in the imperial, Soviet and modern periods [20-21], in relation to German-speaking countries [20, 22], Portuguesespeaking countries [23], countries of the former French Empire [24] and newly industrialized countries [20, 25]. This method, combined with factor analysis and the method of production functions, was also used to study the effectiveness of the governments of post-Soviet Russia [26].

For meaningful interpretation of econometric results, the method of structural analysis of phenomenological data on institutional and innovative events that led to a progressive change in growth indicators and development risk is used. As a conceptual matrix for structural analysis, we used a matrix of cultures built on the scales of Individualism-Collectivism and EqualityInequality [17].

According to this matrix, the culture of Great Britain belongs to an alienating culture dominated by the values of individualism and equality. Based on this assumption, it is suggested that institutional transformations in Great Britain during periods of progressive development correspond precisely to these principles. If, during the periods of progressive development policy, institutional transformations are found that are authentic to the alienating culture and complementary to the existing authentic culture institutions of economic development, then we can state that the hypothesis put forward in our previous works [19] about the connection between culture, institutions and economic development is confirmed.

\section{Results and Discussion}

In the Victorian era, the period of progressive economic policy was the period associated with the reforms of the Conservative government of Robert Peel, who was in power from 1841 to 1846 . Under him, under pressure from free traders, foreign trade duties and indirect taxes were gradually reduced, which was balanced by an increase in income tax, and also was reduced working hours, the Bank of England received central status. These transformations are defined by historians as a great economic reform that led to a drop in development risks and the highest growth rates for the UK economy in the 19th century (see Figure 1).

The institutional competitive advantages achieved in this way in comparison with the rental economies of the main geopolitical competitors of Great Britain at that time were later used for continuous colonial conquests and elimination of competitors. Subsequent Victorian economic cycles can be characterized as extensive, noninnovative development, where risk indicators fluctuated significantly from cycle to cycle, and growth indicators gradually but steadily fell (see Figure 1).

Incomparably less progressive effect in the cycle of 1893-1903 was brought by the democratic reforms of 
local self-government in 1989 and budgetary support for the purchase of estates by tenants.

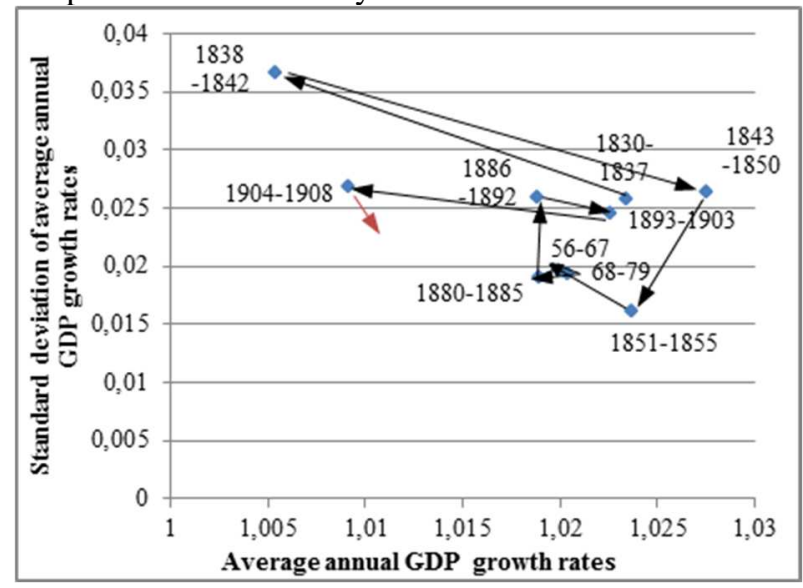

Fig 1. Economic development of the United Kingdom in the periods "The Regency" and "Victorian era" (1830-1837, 18381842, 1843-1850, 1851-1855, 1856-1867, 1868-1879, 18801885, 1886-1892, 1893-1903, 1904-1908).

The second historical period (see Figure 2) of progressive development policy is associated with the land reform in Ireland (since 1903) and its selfgovernment (nominally since 1914, in fact since 1921), the suffragette movement and the activities of the Labor Party. Since 1906, liberal governments have adhered to the course of social or new liberalism: institutions for resolving labor conflicts and social security have been created, working hours have been reduced. The budget of 1910, known as "People's Budget", in addition to rallying the society with social reforms on the eve of the world war, financed military spending, which stimulated economic growth, and ensured the growth of budget revenues through taxes on the rich. Politically, this was achieved by narrowing the rights of the House of Lords and the introduction of professional parliamentarism in the House of Commons, which provided access to this chamber for low-income politicians.

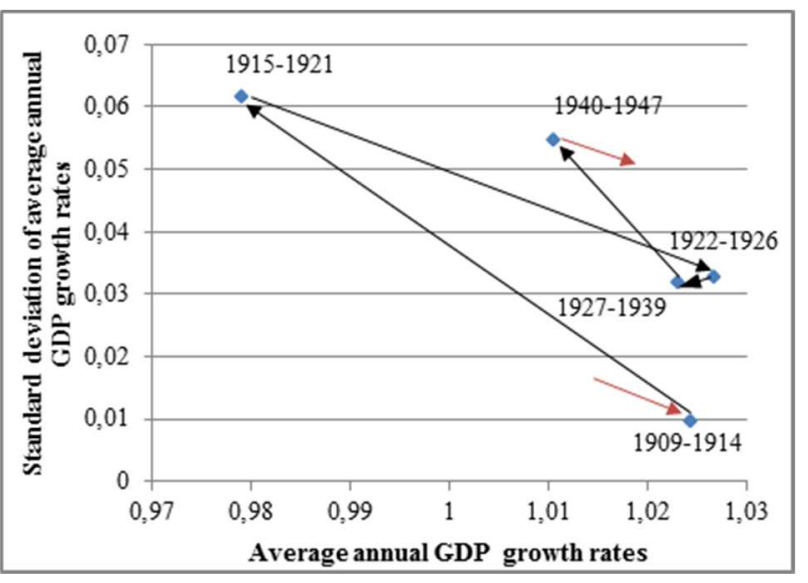

Fig. 2. Economic development of the United Kingdom in the periods "First World War" and "Second World War" (19091914, 1915-1921, 1922-1926, 1927-1939, 1940-1947).

During the period 1922-1926, the post-war recovery economy achieved the growth and risk indicators of the period 1843-1850. This happened against the background of universal suffrage introduced in 1918, the activities of the first Labor government and the continuation of social reforms.

These two economic cycles with progressive development policies have steadily ended in disastrous periods of regression during the two world wars and the Great Depression. The absence in this era of periods with politicians of conservative and aggressive development suggests that the economic system of the British Empire reached the limits of its extensive growth and did not bring the mother country a stabilizing or stimulating effect on internal economic development.

The period 1948-1958 is associated with the Marshall plan and the historical maximum average annual economic growth in the history of Great Britain, achieved in the next economic cycle (see Fig. 3). It began with the continuation of the social reforms of the Labor government and the nationalization of industrial, transport, information and financial organizations, which led to the creation of the "welfare state." This effect of accelerating growth lasted for a long time - 15 years over 3 economic cycles and ended with the final collapse of the colonial empire and a significant loss of opportunities for political domination. A slight increase in risk in the 1959-1962 cycle did not exceed the risk indicator of 1948-1952, which retained the general progressive trend of 1948-1962.

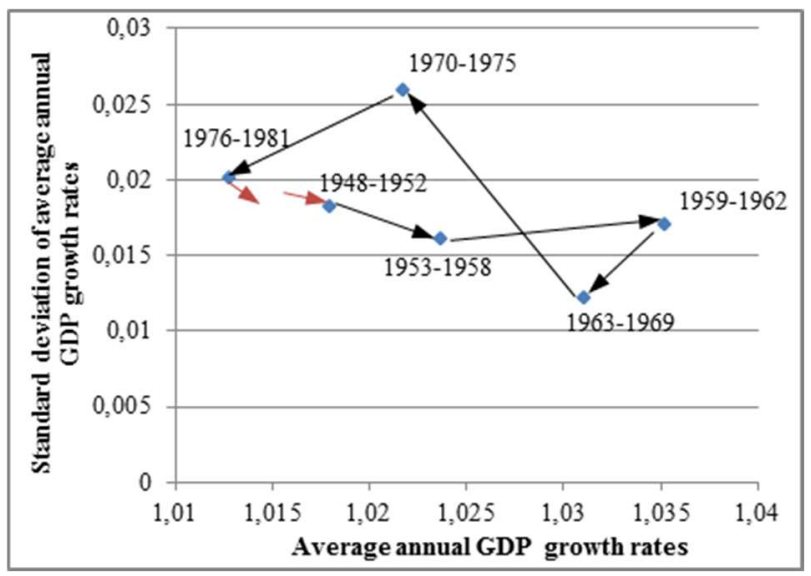

Fig. 3. Economic development of the United Kingdom in the periods "Postwar Britain" (1948-1952, 1953-1958, 1959-1962, 1963-1969, 1970-1975, 1976-1981)

The last, longest period of progressive politics was the period 1982-2001 (see Fig. 4), consisting of the "era of conservatives" and the period of "new Labor". Conservatives, relying on the ideas of monetarism and economic liberalism and using the boom in oil production in the North Sea, adopted a policy of stimulating business activity: suppressed inflation and labor movement, reduced social spending and direct taxes, stimulated the closure of inefficient enterprises and carried out large-scale privatization, thereby freeing up public resources for new investment spurt and formed the society of "People's Capitalism" and "Casino Capitalism". It should be noted that this period was 
characterized by a minimal drop in risks, possibly within the statistical error.

For the second consecutive year, the economic cycle of progressive development policy began with the devaluation of the national currency due to the actions of currency speculators. This has increased the competitiveness of the British economy. The progress was also influenced by the reallocation of resources in connection with the victory in the Cold War and the policy of loyalty to the United States. The New Labor policy combined a market economy, social justice for the most vulnerable strata of society, and the delegation of state powers to local authorities. Compared to previous cases of progressive development policy, this period was the least significant, and ended with a steady regression of the last two decades.

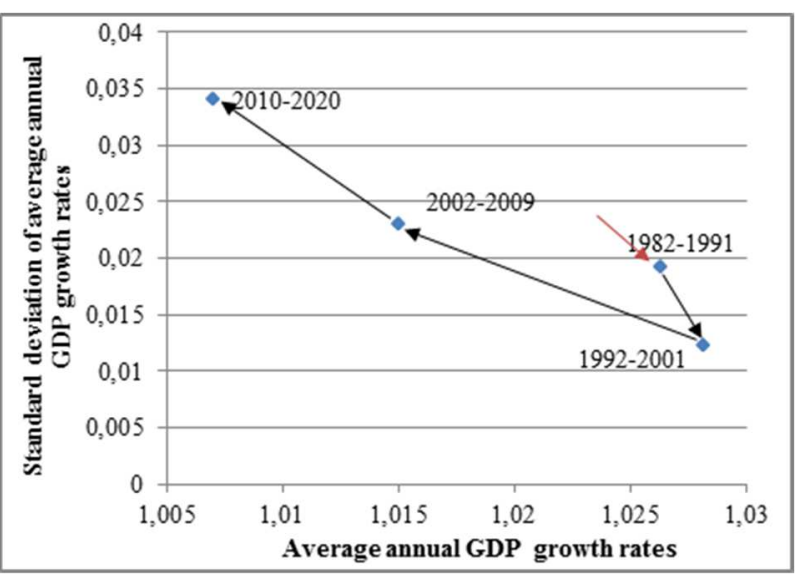

Fig. 4. Economic development of the United Kingdom in the period "European integration"(1982-1991, 1992-2001, 20022009, 2010-2020)

Thus, all known historical cases of simultaneous risk reduction and growth acceleration in the UK are associated with significant institutional innovation. It was they who created the opportunities for increased investment in technical and commercial innovation and the growth of entrepreneurial activity.

\section{Conclusions}

The study showed that the implementation of institutional innovations that are authentic and complementary to the national culture of Great Britain leads to a simultaneous decrease in development risk and acceleration of economic growth, which can be considered the most favorable policy of macroeconomic management of entrepreneurial activity in order to accelerate the use of technical and commercial innovations.

Within this logic, all the changes in institutions identified in the course of the study during the periods of progressive development of Great Britain are aimed at increasing the equality of people and removing barriers to their individual business activity. And the value principles of individualism and equality are fundamental signs of the alienating culture of Western civilization $[19,20,22,26]$.
The methodology used in this study to identify macroeconomic features of an innovative economy makes it possible to apply it to identify cases of progressive development policies in other countries and in different historical epochs, as well as to characterize and assess management impacts on innovation and entrepreneurial activity.

This research methodology makes it possible to identify institutional transformations in the largest countries of the main civilizations of the world during the period of progressive development, to assess what value characteristic of cultures they correspond to, and to classify their cultures according to the conceptual basis adopted here for the structural analysis of institutional transformations. In this case, for different cultures, progressive economic development should be generated by institutional changes that correspond to the value principles of their cultures.

\section{Acknowledgements}

The reported study was funded by RFBR, project number 20-010-00869

\section{References}

1. A. Maddison, The World Economy: Volume 1: A Millennial Perspective, Volume 2: Historical Statistics (2006)

2. W. Easterly, L. Ross, Journal of Monetary Economics, 50(1), 3 (2003)

3. D. Kaufmann, K. Aart, Z.-L. Pablo, Aggregating Governance Indicators, World Bank Research Working Paper, 2195 (1999)

4. D. Kaufmann, K. Aart, Z.-L. Pablo, Governance Indicators, World Bank Research Working Paper, 2196 (1999)

5. A. Helanterä, S.-E. Ollus, Why they, why not we? An analysis of the competitiveness of Finland and Russia, Retrieved from: https://iq.hse.ru/

6. V. Sergeev, E. Alekseenkova, V. Nechaev, Journal of Political Philosophy and Sociology of Politics "Polity. Analysis. Chronicle. Forecast", 4, 6-22, (2008)

7. H. Etzkowitz, L. Leydesdorff EASST Review, 1 (14), 14-19, (1995)

8. L. Leydesdor, Knowledge-Based Economy: Modelled, Measured, Simulated. (Boca Raton: Universal Publishers, 2006)

9. L. Leydesdorff, M. Meyer, Research Policy, 35, 1441-1449, (2006) 
10.L. Leydesdor, G. Zawdie Technology Analysis \& Strategic Management. 22, 789-804, (2010)

11.L. Leydesdor, Entropy, 10, 391-410, (2008)

12.X. Liu, S. White Research Policy, 30, 1091-1113, (2001)

13.C. Botot, D.Satinsky, Innovations. (2011)

14.E. Carayannis, T. Barth, D. Campbell, Journal of Innovation and Entrepreneurship, 1 (1), 1-12, (2012)

15.S. Gackstatter, M. Kotsemir, D. Meissner Foresight. 16, 293-308, 4 (2014)

16.R. Arnkil, A. Järvensivu, P. Koski, T. Piirainen, Final Report on Quadruple Helix Research for the CLIQ project, Working Papers 85/2010. (Tampere: University of Tampere, 2010)

17.M. Saveliev, Multicultural institutionalism: General economic theory of civilizations. The political economy of traditionalism Network Society Project: [monograph] (Izhevsk: "Mitra", 2015)

18.A. Maddison Historical Statistics, Retrieved from: http://www.ggdc.net/

19. Total economy database (TED), Retrieved from: https://www.conferenceboard.org/

20.M. Savelyev, Problemy regional'noj jekonomiki, 3-4. 54-62, (2020)

21.M. Savelyev, N. Pushina, A. Savchenka, E3S Web Conf, 208 03052, (2020)

22. M. Savelyev, V. Ivanov, Yu. Polyakov,. E3S Web of Conf. 222 05009, (2020)

23.M. Savelyev, E. Kutyashova, A. Savchenko, V. Koretsky, Yu. Polyakov, SHS Web Conf. 101 02004, (2021)

24. M. Savelyev, T. Gruzdeva, A. Savchenko, V. Koretsky, N. Pushina, SHS Web Conf. 101 02005, (2021)

25.M. Savelyev, N. Sokolova, Yu. Polyakov. IOP Conf. Ser.: Earth Environ. Sci. 666, 062093. (2021).

26. M. Savelyev, N. Pushina, A. Bryndin, IOP Conf. Ser.: Earth Environ. Sci. 666, 062092, (2021). 